\title{
Getting Ready for the Post-0il Age: The Entrepreneurship as the Rising Star of Development Policies in the Gulf States
}

\author{
Mehtap Isik \\ Department of International Trade Bebek, Bogazici University, İstanbul, Turkey \\ Email: ozcanli@boun.edu.tr
}

How to cite this paper: Isik, M. (2018) Getting Ready for the Post-Oil Age: The Entrepreneurship as the Rising Star of Development Policies in the Gulf States. Modern Economy, 9, 125-148. https://doi.org/10.4236/me.2018.91008

Received: November 28, 2017

Accepted: January 9, 2018

Published: January 12, 2018

Copyright $\odot 2018$ by author and Scientific Research Publishing Inc. This work is licensed under the Creative Commons Attribution International License (CC BY 4.0).

http://creativecommons.org/licenses/by/4.0/

\section{(c) (i) Open Access}

\begin{abstract}
Gulf Cooperation Council countries have been offering opportunities to attract global investors for a while. Yet, the strong tension between the existing government structures and the democratic elements that are needed for investments to flourish creates a complicated economic environment. Besides, the external dynamics sourced from international relations in the region add a new dimension to the problem. For many economies of the same characteristics, governmental supports for entrepreneurial activities rise as a natural solution for many problems. Is it the case for the Gulf States, too? This study, first, draws a framework in order to explore the extent of the new entrepreneur-led growth policies in the region and relates the possible policies to the existing economic problems. Then, three markets, the Kuwaiti labor market which is a good representative of other Gulf States' labor markets, renewable energy markets and biotechnology markets which have increasing roles in new industrial policies, are studied to examine the challenges and the opportunities created by these government policies. The study reveals numerous opportunities offered to entrepreneurs and investors, however further requirements to improve the conditions necessary for entrepreneur-led growth are advised as policy purposes.
\end{abstract}

\section{Keywords}

Entrepreneurship, Economic Growth, Gulf Cooperation Countries, Industrial Policies

\section{Introduction}

As the importance of entrepreneurial abilities are emphasized by academia in 
recent decades, both the industrialized and developing economies in practice, are focusing their policies on innovation and technology creation. Because one of the most important engines of research and development (R \& D) is the entrepreneurial ability, the entrepreneurs' role in this policy transformation is of special interest. This study focuses on the causes and effects of new growth policies followed by the Gulf States to manage the economic activities in getting ready for the post-oil age. The opportunities and challenges created by these policies and impact of the policies on entrepreneurs and investors are the major concerns of this study.

Unfortunately, the conflict environment in the Middle East North Africa region is not providing the necessary pre-conditions for a sustainable economic growth of the countries in the region. The political environment and monarchial structure of governments also are not helping in taking healthy economic decisions. Yet, for the last ten years, the World's economy has been enforcing the policy makers in the region to diversify the economic production and to support the markets. Figure 1 shows that since 1960 the World's output has increased almost eight times. Obviously, the production boom of the last half century has been reflected on energy demand, too. Taking the major production technologies and the available energy resources of that time into account, almost 95\% share of fossil fuels in total energy consumption in 1960 is not surprising. However, Figure 2 shows that the use of fossil fuels has decreased over time. Not only the improvement of technologies related to the alternative energy sources such as renewable energy, also the volatile oil prices and the stringent control of oil producer countries on oil supply starting from mid-1970's motivated the industrialized countries to exert efforts in adopting their production process to alternative energy uses. Industry 4.0, which can be simply defined as a set of strategies to equip industries with less costly and more environmental friendly, new technologies to create and enhance competitive advantage for developed countries against the competitive advantage of unskilled-labor intensive industries in

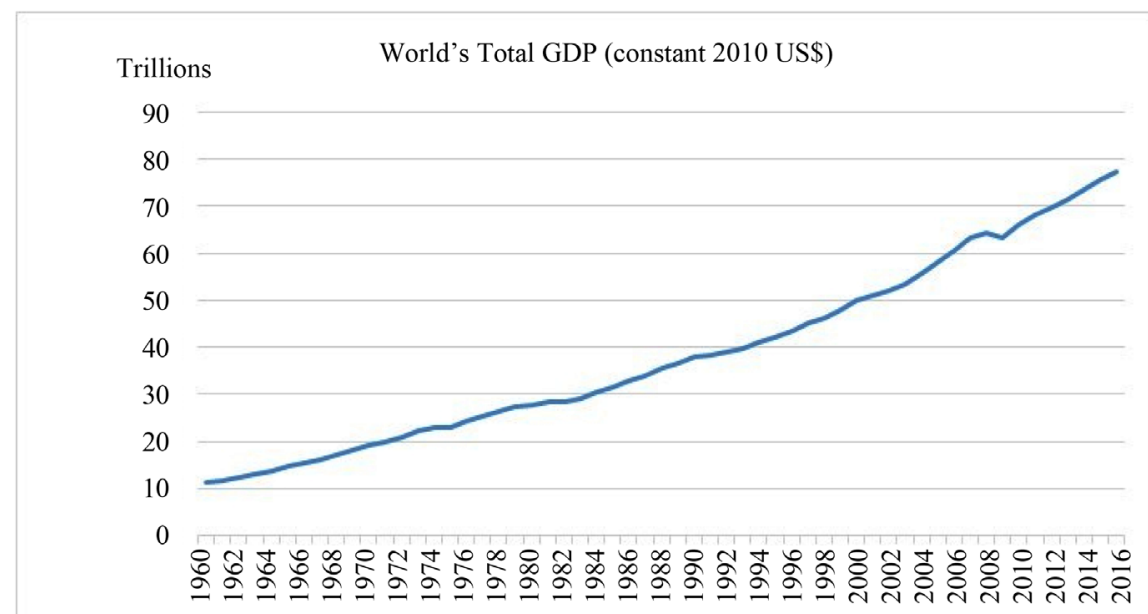

Figure 1. World's total ouput. Source: https://data.worldbank.org/. 


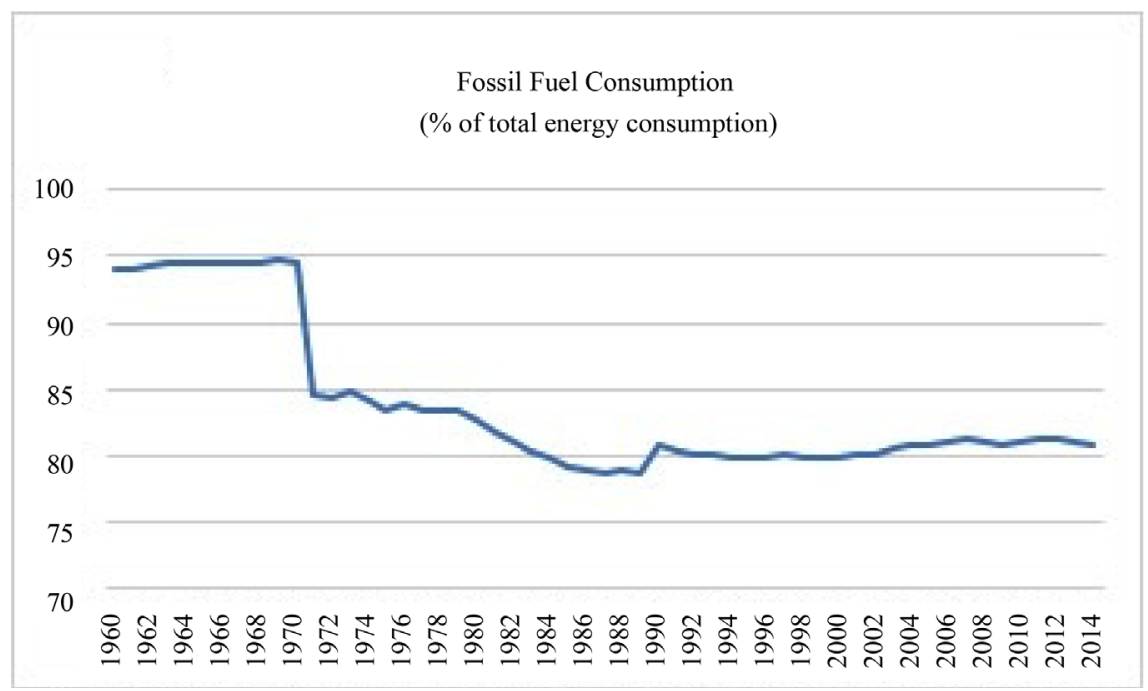

Figure 2. Share of fossil fuel consumption in total energy consumption. Source: https://data.worldbank.org/.

developing countries is a strong example of such efforts. The oil dependency has been a problem for industrialized countries for a long-time period. The increase of use of alternative energy sources is only $\% 10$ over 50 years but recently in an accelerating trend. As Figure 3 shows, the world oil supply has been more than the demand for the last two years. All the evidence shows that oil dependency of industrialization period is coming to the end and a new period in industrialization that can be named as a post-oil age is coming, enforcing the oil producers to take precautionary actions. In Figure 3, projections point continuation of low oil prices. The oil demand growth is expected to decrease in the following years including last quarter of 2017. Price of oil decreased to under $\$ 45$ per barrel lately, driving a 23 percent fall in export revenue for Gulf Cooperation Council (GCC) countries from 2014 to 2015. The decrease in oil income has created additional problems in the region such as a liquidity crisis in the banking sector, increasing costs of borrowing, and increasing dependency to Chinese markets. China's share is estimated to reach $\$ 160$ billion in the export market and $\$ 135$ billion in the import market by 2020 . Although trading with China, a leading oil consumer, an effective strategy to smooth out the effects of decreasing Western demand on GCC oil, this leaves GCC economies exposed to the Chinese economy, facing many risks [1].

An obvious cure to adverse economic effects of volatile oil prices is the diversification of the production in the economy, and an obvious cure to high exposure to a dominant oil demander is the diversification of trading partners. These procurements are now at the agenda of policy-makers in the region, but liquidity-troubles raise the price of capital in GCC countries, and make it difficult to realize the policy changes. The increasing government budget deficits has been financed through issuing sovereign bonds in all of six GCC countries since 2014, confronting the risk of crowding out the private investments in the region. In 


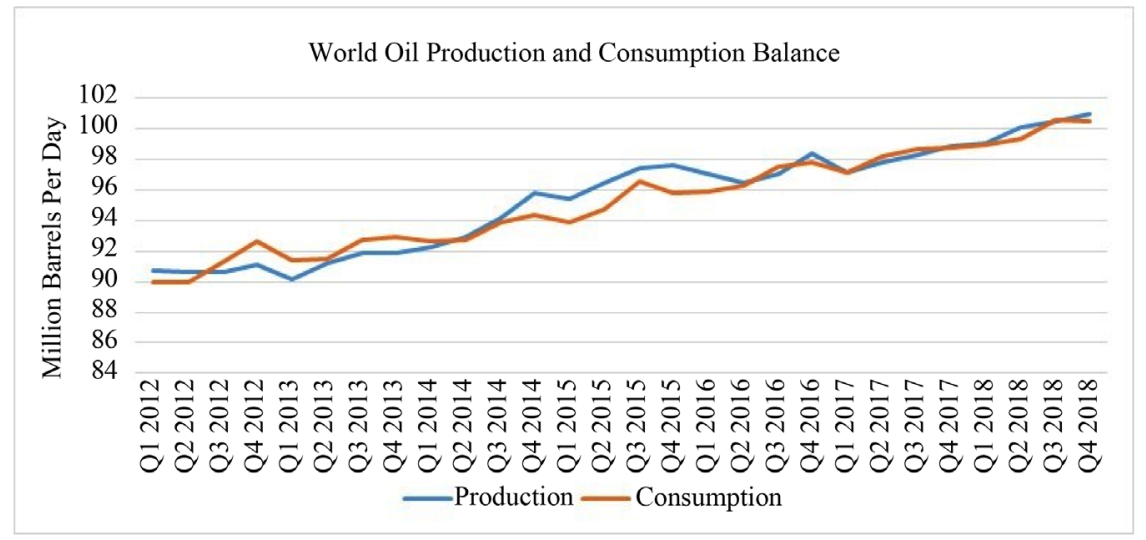

Figure 3. World oil production and consumption balance. Source: Short-term Energy Outlook, November 2017.

addition, taking the adverse effects of sovereign debts on the private sector, which is planned to be expanded, GCC governments are reforming their policies further towards foreign investors. Thus, these reforms can attract foreign entrepreneurs towards GCC countries.

According to the GCC Statistics Center, in 2014, the combined GDP of the GCC countries was $\$ 1.6$ trillion, and more than half of that value, $\$ 861$ billion, was coming from exports. The foreign direct investment (FDI) stock held in GCC countries was $\$ 311$ billion; $\$ 216$ billion in Saudi Arabia, \$20 billion in Oman, $\$ 18.7$ billion in Bahrain, $\$ 31$ billion in Qatar, $\$ 15.3$ billion in Kuwait, and $\$ 10$ billion in the United Arab Emirates. The GCC region appeals to foreign investors, due to not only its large size, but also its increasing openness to international trade and potential capacity for entrepreneurs. World Bank Report, Doing Business 2017: Equal Opportunity for All (2017) analyzes and compares 190 economies in terms of business environment and points two GCC countries, United Arab Emirates (UAE) and Bahrein as two of the top ten global improvers especially in opening their economies to foreign investments. In the near future, the FDI inflows to GCC economies is expected to increase at higher rates as a result of the world economies' recovery and the governments' policies that aim to attract foreign investors.

Unfortunately, the policies of GCC countries send two sharply contrasting messages to the interested investors. The removal of some regulations and reductions in the existing red tape is strongly encouraging. On the other hand, continued restrictions on foreign labor and widely varying business regulations remain to complicate projects and frustrate growth in entrepreneurial activities. Historically, the GCC governments have possessed strong control over their economies. Although they progress towards market liberalization, the timing and the form of policy changes still make it possible that governments can influence the direction of the economic development. In this study, analysis of renewable energy and biotechnology industries in the region exemplifies that investors who managed to overcome these challenges however, may enjoy these 
regulations as a protection shield that constructs a "welcome" barrier to any potential competitor: A conflicting process for creating entrepreneur-led growth.

This study aims to combine a macroeconomic perspective on explaining why entrepreneurial activities are important for GCC economies' development and a microeconomic perspective on analyzing the business environment in GCC, focusing on the challenges and opportunities waiting for the entrepreneurs. It uses case analysis method to explore and explain these challenges and opportunities that are majorly sourced from geographical, institutional, and cultural factors, and searches for the further requirements to achieve successful results. To this aim three markets are analyzed as case studies.

The first market is the labor market in Kuwait, which is a good representative of labor markets in GCC countries. The analysis explores the need for entrepreneurs through investigating the existing problems, and potential ones with the expansion of private sector. Entrepreneurial activities rise as a natural solution for the problems. The second one is the renewable energy sector, and also ecological modernization efforts are studied. The analysis explores the rationale behind supporting an industry by governments' policies. It explains that environmental concerns are not in the focus of GCC governments' agenda. However, as oil incomes become more volatile and the climate change becomes increasingly threatening, the solar-power industry in GCC countries could be taken as a serious new opportunity for GCC investors and entrepreneurs. Third case on search is the biotechnology sector. The analysis explores the role of institutions in development of subsidized industries. It explains that entrepreneurs in the GCC countries can benefit from government's R \& D subsidies if more collaboration among the institutions is accomplished.

The organization of the paper is as follow: The second section reviews the related growth theories in order to draw a theoretical framework in analyzing the attitudes of GCC governments towards economic liberalization. It brings the related literature in for questioning the role of entrepreneurial activities in GCC countries' development policies. Next two sections discuss the major challenges and opportunities that entrepreneurs face in GCC countries, in theory and in practice. The study uses case studies in the fifth section to analyze these challenges and opportunities. It concludes with the discussion of the further needs in policies, taking both the domestic and international impacts of entrepreneurial activities into account.

\section{Theoretical Perspectives}

\subsection{Entrepreneurial Activities and Growth}

Classical growth theory, which is criticized to be left wanting, regarding the empirical evidence, emphasizes the capital accumulation as the major determinant of economic growth that is triggered by random technological shocks. New growth theory extends the classical growth theory by arguing that the capital accumulation and technological improvements are the results of economic growth 
as well as the cause. The new growth theory focuses on the ability to invent and utilize new technologies. In that respect, the theory emphasizes the importance of knowledge. The utilization process creates spillovers so that knowledge and the new technology endogenously accumulate by the incorporation of Schumpeterian entrepreneurial ability [2]. In that respect, the knowledge spillover theory of entrepreneurship underlines the important role of individuals in the economic growth. The theory relates the spillover of the tacit knowledge and the entrepreneurship. It explains the entrepreneurial opportunities that were generally assumed exogenous in the growth theories, as endogenous being transformed from the new knowledge by a special set of skills, intelligence, and vision.

In that respect, the entrepreneurial ability, which is the source of creation of the new knowledge, technology, and consequently the economic growth, is sourced from the knowledge. Therefore, it should be supported by a proper environment. The financial markets are a special part of the required environment. In order to cover the costs, especially R \& D costs, entrepreneurs seek for help from financial markets. Investments on entrepreneurial activities certainly bear risks of entrepreneur's failure. Moreover, the other macroeconomic measures of the hosting country may impose additional risks. Therefore, governments' policy actions result in significant consequences, some of which may be detrimental on entrepreneurial opportunities.

\subsection{Use of Foreign Direct Investments}

Related literature does not argue against policies to attract foreign direct investment (FDI) even for fragile transition economies, but it does give a reason to be selective. Theories backed up with new growth theory supports the use of FDI, not because FDI is a financial source, but the transfer of technology and the innovations that comes along with it may trigger a technological expansion. Instead of relying on a few sectors, extending the production over different sectors is more favorable in terms of both economic growth and social development [3]. The GCC economies, rentierstates having troubles with volatile oil revenues, are in desire to follow new, productive, and effective development policies, like many other growth-oriented economies. Thus, they should try to attract new entrepreneurs in sectors such as technology-intensive sectors that have many "spillover effects" by giving rise to new technologies and knowledge.

\subsection{Industrial Policies: Investing on the Right Sector, Developing the Right Institutions}

Due to almost-collapsed market economies after 2008, the idea of using industrial policies and coordinated government actions to support certain industries became a broad consensus [4]. However, directing the national resources towards chosen industries to restructure the economy may dramatically fail, resulting in many unexpected consequences. The success of industrial policies de- 
pends on many factors. Due to the uncertainties in human interactions, the structure and quality of existing institutions is of special importance in achieving efficient exchange mechanisms. However, not all economies give rise to strong institutions that lead growth and development. Indeed, in some economies malfunctioning institutions is the major determinant of stagnancy in the society [5]. The existence of the resources does not guarantee the success. Especially, the developing economies, which can quickly absorb the existing technologies from the industrialized countries generally, have trouble in the production process. Contracting failures explain most of the differences in technology diffusion among countries of similar resource capacities.

The successful industrial policies cannot be guaranteed, but the following conditions work to draw a theoretical framework. First, the legal framework, and how they are applied play a crucial role in the business environment. In that respect, even if unintentionally, the government is always a part of the economic activity. Second, unrealistic development goals result in failure. The endowments and comparative advantages of the economy have to be taken into account in developing the economic strategies. Third, the learning society, which is able to disseminate higher rate of technological progress is the leading actor of sustainable growth and development. Given the fact that the markets are not efficient in producing public goods, government should follow a proper prescription carefully to increase the learning capacity of the society. Fourth, governments can stimulate innovative entrepreneurial activities, which constitute a motion engine of the learning society, only through a well-designed program. Government's provision of required infrastructural investments and coordination of collective activities are sine qua non in facilitating the clusters that can ease many challenges faced by entrepreneurs. The quality of the instruments and the way that they are practiced are as important as choosing the proper instruments and targets [6].

\subsection{Institutions in Managing the Entrepreneurial Activities}

Studies show a two-way link between the institutions and entrepreneurial activities. The existing institutions shape the entrepreneurial activities in many dimensions such as number, effectiveness, and probability of success. In addition, the entrepreneurial activities make the institutional changes. Individuals and organizations are increasingly engaging in creative activities, making the elements of counter-culture be transformed into social entrepreneurship, and enforcing an institutional change. Moreover, institutional changes that result from entrepreneurial activities occur, unexpectedly [7]. Although it is not the direct intention of the entrepreneurs to change the institutional structure in the society, the self-interested purposes of their activities cause the required changes. An entrepreneur, driven by profit incentives, introduces new products and new activities to markets, which have not been available earlier. In this regard, entrepreneurs coordinate markets across space and time, and accounts for technolo- 
gical progress and growth, effectively. In order to benefit from the entrepreneurs' ability, they must be given at least a controlled freedom to act on their ideas [8].

Bringing different literatures together, it can be concluded that without the governmental support, the contribution of entrepreneurial activities to growth and development process is only limited, and even sometimes result in rise of malfunctioning institutions and systematic errors in production. However, the government's hand in the economy should not restrict the entrepreneurs' capacity to coordinate the markets and transform the economy.

\subsection{Theories in Action in GCC}

Kamal El-Wassal shows that trade liberalization in GCC region is statistically and positively correlated with imports and trade balance, only because of oil exports. When he excludes oil exports from his calculations, he finds that trade liberalization has a negative effect on the trade balances of Arab countries [9]. Because of the institutional weaknesses, poor physical infrastructure, and lack of skilled labor in these countries, these results are not surprising. Due to the current low price of oil and its long-term unsustainability, El-Wassel's results [9] have strong policy recommendations. Especially, oil revenue dependent GCC countries must attract investment in more sectors, while developing their infrastructure, finding a dependable source of skilled labor, and working on the necessary institutions.

Al-Iriani in 2007 [10], finds a bi-directional relationship between FDI and GDP in the GCC countries i.e. inward FDI have increased the GDP growth, and at the same time, high GDP growth has attracted more FDI into GCC countries. Although these countries have the potential to finance their own development through their domestic investment, FDI provide the "spillover effect" that is acclaimed by endogenous growth theories. The inward FDI has the potential to provide more than what the accumulation of physical and human capital can add to the economic growth. Opportunities to improve the existing physical and human capital, facilities that ease the transfer and diffusion of new technologies, systems to increase the managerial efficiency and entrepreneurial abilities are only few of the benefits.

The oil sector in GCC has little linkages with the other sectors and provides little technology transfer and innovation. Therefore, high FDI flows to the oil sector are not favorable. GCC countries should be selective in attracting FDI. Because of the bi-directional causality between GDP growth and FDI in GCC countries, growth is an important measure to attract FDI [10]. However, policies directed only to attract FDI may not be sufficient, and instead efforts should be directed at other sources of growth. Policies that are supposed to attract inward FDI and to lead long-term economic growth should also prevent the negative short-term effects of investments. In this regard, well-organized and well-managed institutions should support the policies and follow up their performances. 
Theoretical and empirical studies support selective policies followed by GCC countries in their economic transformation. The policies should aim to attract higher investment in sectors with large knowledge spillover effects, to diversify the economy to be less reliant on oil industry, to develop physical infrastructure and human capital. GCC countries, which are conservative with weak institutions historically, are planning, at least on paper, to renovate and found institutions that can lead effective entrepreneurial activities. The new institutions are to choose and attract appropriate kind of FDI through establishment of investment agencies, to improve the local regulatory environment and rule of law, to develop the local financial markets, and to follow up the performances of transparent macroeconomic policies. On the contrary, new social institutions built upon the freedom for entrepreneurs are generally harmful to the monarchic structures of the states, and this is where the conflict arises.

Considering the Middle East and North Africa region for its economic measures, institutions and culture, the development policies that do not take the sociological structure of the region and existing institutions into consideration cannot be successful. The existent monarchies and dictatorships in the region are not compatible with market systems, and the expectation of a fast democratization process is naïve. However, the rulers are more open to use of national innovation systems to develop a private sector, which is dominated by entrepreneurs. In that sense, entrepreneurial activities can cure many immediate growth and development problems, while leading a way to future democratization in the long-run. Although the regulations may distort business environment, harm creativity, and innovation incentives of entrepreneurs, the supports may provide profit opportunities. In that sense, the role of governments is both destructive and constructive, at the same time [11].

\section{Challenges}

Growth of GCC has been halved since 2014, "growing by oil and slowing by oil" [12]. Some of the challenges most often associated with the business environment in the region, such as high unemployment, labor market rigidities, scarcity of skilled labor, the large share of public-sector employment, the problems caused by weak education system and strong regulations, are addressed in this section.

The problem of high unemployment among nationals, especially the youth unemployment is expected to increase because of increasing labor supply, waning public sectors, skill mismatches, high reservation wages, and rigidities in labor and product markets. In response to high rates of unemployment, nationalization of labor force has been the primary policy of the governments in the region. For a long time, the governments in the region are following labor market policies and regulations to substitute the nationals for foreigners. However, the regulation of labor market and enforcement of nationals' employment also result in the labor market inefficiency in GCC. The nationalization policies are applied 
through different means across the region, from use of quotas on number of nationals employed to employment barriers for foreigners and complicated dismissal regulations for nationals. Bahrein and Oman have been using relatively more market oriented policies to create incentives for nationals to be employed in private sector rather than waiting for public jobs. The public-sector jobs have been regarded as a way of distributing the oil revenue in the country for many years. In this respect, the employment policies of dominant public sector create significant differences between the working environment of public and private sectors [13]. Through the nationalization policies, governments have been trying to shift the employment structure from public dominant to market oriented. However, the success of these policies is arguable. Whether the nationalization policy working or not, the size of the unemployment problem indicates that these regulations will not be removed soon [14]. The effect of nationalization policies on entrepreneurial activities is complicated. These policies both constitute incentive for young people to start their own business instead of waiting for public jobs and at the same time cause higher explicit and implicit costs for the foreign investors and prevent their entry to the country.

Labor that is supposed to be a variable factor of production is transformed into a semi-fixed one by nationalization polices and poor education system. The education system in the GCC countries has improved much in the last few decades in quantity, but the quality is of question. Firms in the region still complain about nationalization policies that oblige them to employ the low skills or mismatch of skills that result from the inappropriate means and methods used in education and not elaborating on required skills for non-oil sectors [15]. As a result of nationalization policies to some extent, the segmented labor market is a characteristic of the region. Many skilled workers accept unskilled labor jobs, but the unemployment rates are highest among the more educated employees. At the same time, public sector offers better opportunities with lower expectations, causing lower incentives for young generations to improve their skills. Compared to private sector, public sector jobs offer greater job security, higher wages, and more benefits. Being more interested in public-sector jobs, which value diplomas over skills, education choices are more likely to be irrelevant to market demand. Nationals rather prefer waiting for a public-sector job. Indeed, more highly educated are willing to wait longer [16].

The large public sector increases the fiscal burden on countries, and inhibits long-term solutions through crowding out the private sector. Inefficient job creation in public sector increases the fiscal burden on the state and limits the resources for the private sector to innovate and to revitalize the economy. Due to the decreasing oil revenues, governments in the region feel the fiscal burden of the large public sectors more strongly. A policy change regarding the public employment is not surprising. In that sense, the opportunities exist or created for entrepreneurs are of special importance in the region.

Strict regulations constitute a major problem for entrepreneurs. Regulations 
on recruitment and dismissal are more restrictive in GCC than any other emerging market; firms in the region identify labor regulations as the major constraint in expanding their businesses [17]. The labor market rigidities significantly limit the job creation in private sector in the GCC and slow down the firms' responses to positive changes in the economic climate. In order to encourage the private sector to create new jobs for the millions of young people joining the labor force in the next few years, GCC countries should improve the regulations of the labor market.

A competitive business environment is highly advised in fast-growth oriented studies [16]. However, the business environment of transition economies may be fragile to face such competition. A gradual transformation into a more competitive market can be a good start to provide incentives for entrepreneurs. Reduction in entry barriers curbs incumbents' market power and rents. Stronger competition in GCC markets will also reduce the bargaining position of employers and be essential to raising growth rates over the long term.

Instead of short-term solutions to economic problems in the MENA region, long-term focused reforms should be designed. Especially, under recent political concerns and conflicts, growth oriented steps are not expected to be taken. Policies such as promoting local employment or supporting incumbent companies are unlikely to be changed [18]. In that respect, foreign entrepreneurs who are interested in doing business in the GCC countries are enforced to handle the challenges. However, changing political order and decreasing oil demand forcing the policy makers to adopt more economic reforms than they like to do in the GCC states in the near future.

\section{Opportunities}

Opportunities for entrepreneurs in the region majorly stem from the adaptation strategies of GCC governments, focusing on government-supported infrastructure, research-intensive industries, and labor-intensive small and medium-sized enterprises. The financial services industry, possible privatizations, and policy changes related to the oil industries are also potential sources.

Infrastructural projects not only provide jobs in the short-term, also boost long-term economic growth by the accumulation of both human and physical capital. GCC countries already have the best infrastructural services in the MENA region, but market oriented new polices require new infrastructural investments that give many profit opportunities rise. In addition, infrastructural projects constitute significant source for job creation to confront the expected unemployment in the next few years. As of 2016, infrastructure services and construction in total employ approximately 20 percent of the employed labor. It is estimated that through 2020, GCC countries need to commit approximately 6 percent of their GDP into infrastructural development in order to maintain the current momentum [19].

A small number of domestic actors dominate the GCC banking sector and the 
majority of ownership rights belong to the governments. The prospected liberalization of the banking sector can help countries to achieve economic diversification through expanding credit opportunities to entrepreneurs, small and medium enterprises. GCC countries are World Trade Organization (WTO) members, and commitments enforce each country to at least some degree of liberalization in their banking sector. However, trade reforms vary from one to another, being joined the WTO on different times. In order to both meet the commitments by General Agreement on Trade in Services (GATS) and ensure longterm growth, the banking sectors are likely to become much more competitive in recent years. Possible asset sell-offs in banking sector points to interesting investment opportunities [20].

How the investments are allocated and the strategies are implemented are more important than the total $\mathrm{R} \& \mathrm{D}$ expenditures. A comparative analysis of GCC countries with BRIC countries (Brazil, Russia, India, and China) reveals that these countries invest heavily in research and development, and use national innovation systems in developing human capital, establishing an $\mathrm{R} \& \mathrm{D}$ environment, and developing a future-oriented industrial base [21]. The R \& D activities are still mostly led by government investments and have not yet followed by the private sector. Although the use of national innovation systems and dominant role of the governments in growth is still subject to discussion, this approach certainly offers an opportunity for those entrepreneurs in the GCC region, who can take advantage of highly government subsidized local R \& D activities.

If $\mathrm{R} \& \mathrm{D}$ activities are to be centrally planned, the high-quality institutions are specifically important. Early efforts in developing a private-sector marine biotechnology industry in Oman that has diverse, living marine resources and rapidly growing educational and $\mathrm{R} \& \mathrm{D}$ infrastructure to develop a commercial marine biotechnology industry were not completely successful because of the lack of collaboration between research institutions [22].

Characteristics of geographical sources are as important as high-quality institutions in development process. Given the general weather condition of the region, GCC has a significant potential and comparative advantage in solar-power generation. Production of large amounts of solar energy to export, which is recently in the agenda of all GCC countries, fits in many strategic plans, which target economic growth and social development at the same time. Solar-power, which becomes a strong alternative to oil with the recent technological developments in energy efficiency, is expected to reduce burden of highly subsidized domestic energy consumption. In order to accelerate the development of the solar-power sector, governments' efforts in stimulating the R \& D activities and new solar-power innovations prepare GCC infrastructure for a post-oil age. These potential benefits are combined with public attention of acting against climate change in GCC countries and in the world [23].

Table 1 summarizes the challenges and opportunities that are discussed 
Table 1. Challenges and opportunities for the entrepreneurs in the region.

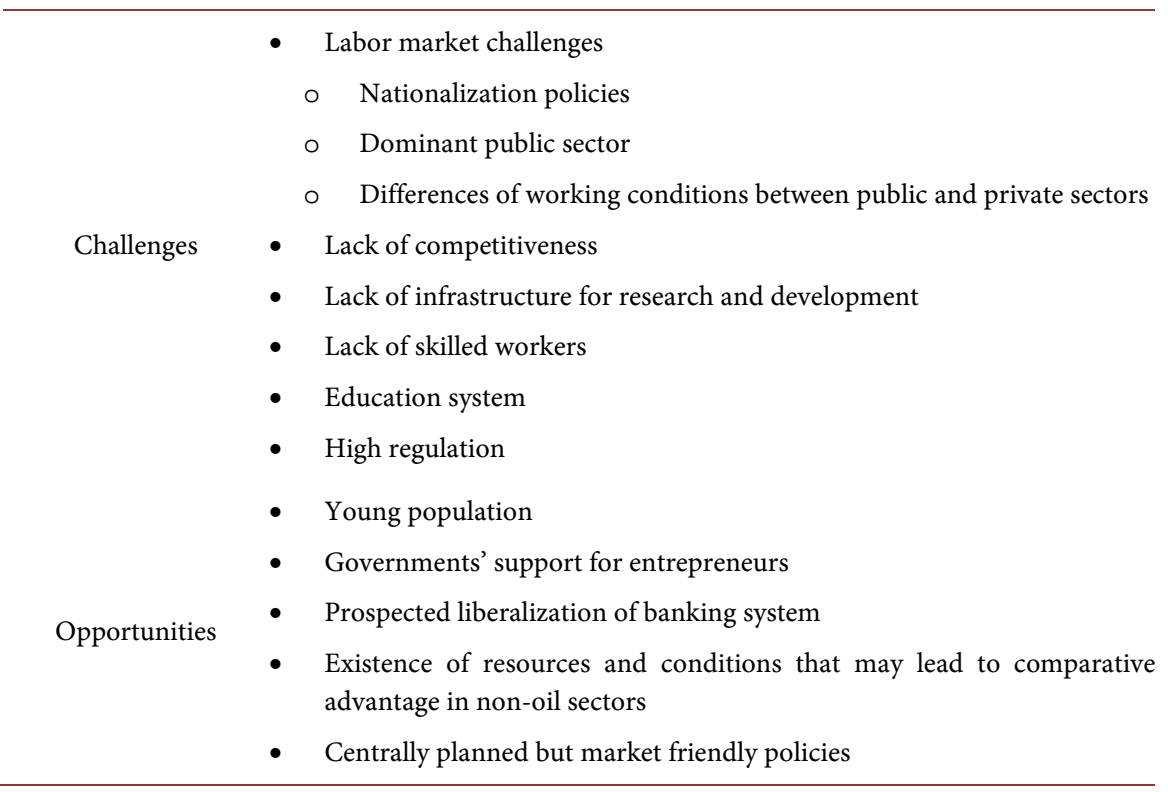

above. The cases studied in the section 5 explore and exemplify these challenges and opportunities.

\section{Cases}

\subsection{Kuwaiti Labor Market}

The Kuwaiti labor market is a good representative of the larger GCC labor market. As of June 2016, 55 percent of the total Kuwaiti population is under the age of 25 and 19 percent of the total population is between the age of 15 and 25, pointing on the high rates of entries to labor force. 76 percent of Kuwaiti workers are working in government sector and only 21 percent is working in the private sector. 65 percent of non-Kuwaiti workers are working in private sector. A high youth unemployment rate among nationals is the major problem, and it is clear that it will continue for some time. Like other GCC countries, Kuwait has been relying heavily on oil revenues to provide jobs in state owned and related enterprises. However, given the current employment and population statistics and decreasing oil revenues, the government sector will be unable to offer the existing conditions to large number of young Kuwaitis entering the labor market. Moreover, the private sector as of today is not expected to be able to provide the jobs needed to handle new entries to labor force.

Kuwait is one of the first countries in GCC in realizing the oil revenue threat and acting to take precautionary policies. As policy-makers in Kuwait enact new laws and create various incentives, the number of private businesses is continuously growing. However, the expansion of private business environment is mainly utilized by a few "well-known merchant families," which have developed as quasi-monopolistic entities over the last few decades. Although the growth of job creation in private sector has been higher than the growth in public sector in 
recent years, the concentration of entrepreneurial activities among a few families does not seem to be evidence of a well-functioning free market.

In order to deal with youth employment, the Kuwaiti government, like the other governments in the region, has been exerting efforts to nationalize the labor force, which is called "Kuwaitization" for more than a few decades. The process involves providing priority to national candidates in public sector hiring. At the same time, Kuwaiti government has been encouraging the private sector to follow the same procedure.

There are two main challenges in adaptation of the private sector to "nationalization" process, other than the availability of jobs. First challenge is related to the difficulty of matching the needs of the private sector to the skills, qualifications, and experiences of workers in the labor market. The focus of higher education in the region is often towards public employment, prioritizing the degrees offered by diplomas over the development of marketable skills. The second challenge is sourced from the general attitudes towards private sector jobs among GCC nationals. Kuwaiti workers are reluctant to accept the terms and remuneration offered in private sector, which are stricter in compared to ones offered by public sector. Traditionally, public sector jobs are simply a mean of distributing the country's oil revenues.

The primary data gathered through surveys points that many Kuwaiti nationals prefer to wait for un-demanding, clerical-type job positions in the public sector rather than joining the existing competitive and demanding jobs in the private sector [24]. Private sector generally offers lower starting salaries than public sector in GCC countries, but higher wages opportunities are offered to reward efficient performances. Surveys show that Kuwaiti employees perceive efficiency wages as risky and low starting salaries as permanent. In GCC countries, public sector jobs are preferable because they are more secured and less demanding than private-sector jobs. Regulations in public sector offer surprisingly wide-range of rights. Kuwait's Annual Leave Report in 2011 revealed that only half of workers regularly were attending the work. Many employees used to absent under various excuses and even some without any excuse.

Having a well-functioning private sector and a successful adaptation process in the labor market is a priority for GCC governments. Recent policies, which focus on the differences between the working environment in public and private sectors, target to change Kuwaitis' apathetic attitude towards business environment. Kuwaiti government uses three laws to govern the Labor Market: Labour Law for Government Employees, Labour Law of Oil Sector for those in oil sector and Labour Law of Private Sector. Three laws together organize the transformation period in the nationalization and privatization process. In December 2009, Kuwaiti Parliament approved a new draft of Labour Law, in order to deal with the challenges in the adaptation process.

The new labor law since 2010 is to ease the transition from high-wages highbenefits jobs in the public sector to low-starting wages low-benefits jobs in the 
private sector, the government has stepped in to provide the same benefits given to public sector employees to those working in the private sector. For example, the new labor law gives the employees the right, not to be dismissed unfairly. A minimum wage is introduced, too. These regulations obviously create a burden on the Kuwaiti government's budget, which is not easy to handle for a long time, due to the decreasing oil revenues.

Besides increasing the workers' rights in private sector, the changes aim to reduce the attractiveness of the public sector. In the transformation period, job positions in public sector are being pushed to perform at higher levels of efficiency, requiring higher quality, skills, and productivity. The government's demand on higher skilled labor is expected to affect the choice of employees between public and private sector. The Kuwaiti government is fighting against the traditional inefficiency of the employees in public sector. For example, in February 2017, salaries of 900 employees in public sector have been suspended because of their absence without any notification [25].

The problems and solutions to these problems in Kuwaiti labor market are relevant to the privatization process. A strong private sector can offer rights to appeal employees' interest and give them incentives to build quality and the necessary skills. An efficient way of constructing such a private sector and reducing the government sector size is the major challenge. The successful integration of young entrepreneurs to the market obviously solves problems of youth unemployment and efficient privatization at the same time. In April 2013, visioning a proper business environment for entrepreneurs, the Kuwaiti government has founded the National Fund for Small and Medium Enterprise Development, which finance up to 80 percent of capital for feasible small and medium projects submitted by Kuwaiti nationals.

Unfortunately, the existing business environment does not seem to be suitable for entrepreneurial activities. Surveys of 502 SME's in Kuwait show that more than 35 percent of entrepreneurs mostly complain about the formalities in starting and running the business such as licensing and permits. Report by World Bank, Doing Business 2017, orders Kuwait as $102^{\text {nd }}$ among 190 countries in Easy of Doing Business ranking [17]. Central Statistical Bureau of Kuwait reveals the self-employed workers as only 0.5 percent of the total workers in 2015 (Labor Force Survey, 2015). On the other hand, the number of SME's in Kuwait is high, especially on retail and non-financial services and employ 23 percent of total workers, but they contribute to GDP at only 3 percent.

\subsection{Ecological Modernization and Renewable Energy in GCC Countries}

Decreasing oil revenues and increasing unemployment in labor market make the governments in GCC search for non-oil sectors to focus on. The requirements for successful industrial policies enforce policy makers to focus on sectors for which the existent comparative advantages can be supported through the exist- 
ing economic and political structures.

In this regard, renewable energy production, solar energy in specific, is a clear target to hit, considering the following three major points: First, comparative advantage created by climate conditions increases the success ratio of industrial policies on solar power sector. Second, such industrial policies also complement other policies, which target to supply a non-oil energy resource for the increasing domestic energy demand and to combat climate warming which is in altering levels in the region. Third, renewable energy production has a strong potential to be expanded by entrepreneurial activities, which also cure the labor market problems in the long-run. Although the costs of producing the same amount of energy change across the region, and the governments' energy and tax policies play crucial role in these differences, researches on energy efficiency show that using hydrocarbons are still cheaper than using solar power or wind power ${ }^{1}$. Then, the need for innovative approaches in order to make renewable energy use more efficient brings higher profit opportunities to entrepreneurs. In addition, the governments' policies are seen to be more successful when they support the entrepreneurial activities in order to create a proper innovation environment. The private sector has to be a part of the renewable energy production if the public policy followed by the government aims to achieve success both on increasing the share of the new sector and effectively slowing down the climate change [26]. In addition, the cooperation structure in entrepreneurial activities has an important role in the successful development of renewable energy sector, which can quickly rise over associative entrepreneurship supported by the government [27]. In that sense, GCC governments' back up for entrepreneurs in the industrial development process is a good start for the business expansion.

The GCC economies revealed plans to increase the production and consumption of clean energy, taking the unsustainability of the existing energy market, the solar resource potential and decreasing technology costs into account ${ }^{2}$. Auctions such as the Dubai auction for a solar park in Dubai, took the prices down to world record low level, competing with oil and natural gas prices in the region [28]. Shareholders from other segments, such as manufacturers, are also encouraged to use solar power via tax reductions etc. The existence of established industries such as aluminum, glass and steel and developed infrastructure appeal the interests of producers. Partnerships between local companies and well-established foreign companies, such as partnership of Masdar with Abengoa and Sener, and acquisition of leading solar developer Fotowatio Renewable Ventures from Spain with Abdul Latif Jameel, are also good signals about development of a local renewable energy sector.

The development of renewable energy sector in GCC supports the govern${ }^{1}$ Annual Energy Outlook yearly published by US Energy Information Administration offer a detailed analysis of energy markets. A huge literature on energy efficiency is beyond the scope of this study.

${ }^{2}$ Arab Future Energy Index (AFEX) 2015-Renewable Energy report published by The Regional Center for Renewable Energy and Energy Efficiency (RCREEE) shows that the solar power generation is planned to constitute between 5 percent and 25 percent in GCC countries until 2020. 
ments' plan to decrease public employments and number of civil servants in the region. Estimates by IRENA shows that 140,000 job positions on the average can be created by renewable energy sector in 2030 . The forecasts show that the successful development of renewable energy sector can solve labor market problems and create jobs for younger generations.

The renewable energy sector is estimated to bring cumulative savings on fuel for the region almost 2.5 billion barrel of oil [28]. Other than the fiscal benefits, the possible reductions in carbon footprints, which is significant with estimated value of 8 percent, and the overall reduction of water withdrawal in power sector with estimated value of 16 percent, almost 11 trillion liters of water per year, show that it worth to focus on renewables. The climate change is a major problem of GCC region affecting the food security and water supply. The ecological modernization is a priority in the agenda of governments.

Each of the six oil and natural gas producing countries in the GCC are in the top 15 countries for carbon dioxide emissions per capita: Qatar is the first, $\mathrm{Ku}$ wait is the fourth, Bahrein is the fifth, UAE is the eighth, Saudi Arabia is the tenth and Oman is the fourteenth ${ }^{3}$. Due to their oil revenue dependency and highly oil-biased economies, GCC countries have been among the main actors preventing agreements on international climate change negotiations for years.

The environmental measures are not compatible with the oil-dependent policies in the region. The geography and climate of GCC region is identified by high temperatures and arid lands. The countries face many challenges that are worsened by the global climate change, such as desertification, lack of biodiversity, water scarcity, and rise of sea levels. The temperatures are expected to increase 2 degrees in Celsius by 2050 and to cause drastic rise in sea level sweeping a significant amount of arable lands by the sea. GCC countries have the highest consumption of water per person in the world, and given the current population growth, which is between $1.1 \%$ (UAE) and $6.4 \%(\mathrm{Oman})^{4}$ the water scarcity and food security will be the major concerns of the countries. The countries of the GCC have taken a more pro-active approach towards ecological modernization through various projects, regulations, and industrial incentives.

In terms of public opinion, efforts to combat climate change would be well received. Surveys conducted show that 98 percent of those surveyed in 19 Arab countries believed climate change was real and 89 percent believed it was human-made. Surveys also signaled a desire for greater efforts by their governments to combat climate change; only 35 percent believed governments were doing enough [29]. However, lack of a civil society in GCC countries make it almost impossible that general public opinion about the requirement of governmental precautions to fight against climate warming affects the governments' agenda.

The abundance of oil and the cultural attitudes in use of the oil revenue make it difficult to practice high tax policies for the governments in the region. As

${ }^{3}$ Data obtained from http://data.worldbank.org on June, 2017.

${ }^{4}$ https://www.statista.com/statistics/688561/gcc-urban-population-growth/. 
contrary to Norway where a fund is used to control the oil revenue, a non-oil budget deficit is targeted and a sound tax system is used to finance government expenditures, the GCC countries cannot overcome the oil revenue curse, which create a biased growth on oil-related environmentally unfriendly sectors. The efficient use of such an oil fund is the major concern of GCC governments and is possible only if transparent and accountable transactions can be implemented by high degree of consensus [30]. In addition, the rentier structure of governments in GCC causes inefficient production in oil-related sectors. The governments subsidize national oil companies and oil-related industries, and unsurprisingly regime family/friends manage these firms. These industries tend to over or under produce, creating inefficiency [31].

Low tax rates attract international energy-intensive industries such as aluminum, petrochemicals, and the steel to the region. The FDI inflows intensify mostly on oil-related industries ${ }^{5}$. In a vicious cycle, the presence of many large energy-dependent industries in GCC countries further reduces governments' ability to tax energy consumption, as it would cost the energy-intensive industries' competitive advantage in terms of low energy prices.

On the international level, GCC countries, led by Saudi Arabia, have been a powerful force in blocking climate negotiations. The GCC countries are considered Non-annex I parties i.e. they have no obligations to reduce their greenhouse gas emissions. At the same time, as oil revenue dependent countries, they have been hostile to any international agreement that encourages switching to a low-carbon economy, and would likely reduce global demand for oil. In the last decade, with an incentive to decrease oil revenue dependency and to slow down the climate change's effects, the GCC countries have been trying to get use of any agreement on carbon-reducing policies by tying them with pledges by other countries related to economic diversification and foreign direct investments. In this regard, the GCC countries have begun to take more pro-active role. As Non-Annex I parties, the GCC countries are to be awarded with clean development projects getting also a support in adapting their oil-based economies to a post-oil world. In 2009, International Renewable Energy Agency located the headquarter office at Abu Dhabi. The decision increased UAE's recognition as an environmentally progressive state and gave the GCC region a higher profile in international discussions of energy policy.

At the regional level, the GCC coordinates ecological modernization efforts through the Assistant Secretary General of Human and Environment Affairs, among other organizations. In the past, regional efforts were limited to raising awareness of climate issues among the public, but recently policies that are more substantial have been considered. At a meeting in Muscat in 2009, the GCC countries discussed on implementing a green tax that carries with significant economic and political costs. The GCC common power grid, completed in 2012,

5“Assessing Investment Policies of GCC Countries: Translating economic diversification strategies into sound international investment policies" 2011 report conducted by the MENA-OECD Investment Programme. 
which will reduce the need for new energy by 5000 megawatts, was another focus of discussions. In addition, in 2007, the GCC established a $\$ 750$ million fund for the development and use of cleaner and more efficient oil-sectors related technologies as well as new technologies to combat climate change [23].

On the national level, each GCC country has an administrative unit dealing with climate change issues: The Public Commission for the Protection of Marine Resources, Environment and Wildlife in Bahrain, the Environment Public Authority in Kuwait, the Ministry of Environment and Climate Change in Oman, the Supreme Council for the Environment and Natural Reserves in Qatar, the Presidency of Meteorology and Environment in Saudi Arabia, and the Federal Environment Agency as well as the Ministry of Environment and Water Resources in the United Arab Emirates. However, these agencies usually have weak capacities and little influence in domestic policymaking process. No GCC country has a consistent policy framework for ecological modernization; rather their focus is at the leading projects. The most substantial of these projects is Masdar City in Abu Dhabi, the home of the International Renewable Energy Agency's headquarters. Masdar City was planned as carbon-neutral, zero-waste city in 2008. As of 2017, few thousands of people are living in the city. The Masdar Institute of Science and Technology is the nucleus of the city and creating innovation and supporting entrepreneurial activities in the city. The city is expected to have a population of 90,000, host 1500 companies in the field of sustainable energy technologies commuting with the Masdar Institute of Science and Technology. Another example is Qatar's Energy City, which is planned to be a green city and a business hub for hydrocarbon industry. Nodes like Masdar City and Energy City are intended to lead a diffusion of new technologies across the region, supporting and expanding the innovative entrepreneurial activities.

While the GCC countries as energy exporters are getting ready for beyond the oil age, they realize the importance of innovation process and the role of private investments in it. In supporting the entrepreneurs, they offer many opportunities although these are not well organized, yet.

\subsection{Biotechnology Sector}

An efficient biotechnology sector can offer solutions to water and food problems and transform the healthcare industry so that the increasing financial burden on the GCC governments may decrease. At the same time, it can serve for the other MENA countries' needs by gaining competitive advantage in international markets. The Gulf by itself provides a regional advantage for GCC countries to create such a competitive advantage. However, biotechnology production is an intensive R \& D process. It requires other factors than the physical capital, such as high engineering and scientific skills, which are missing in the region.

The share of R \& D spending in GDP of GCC countries have been always significantly less than the world's average. As of 2013, Israel has the highest share of $\mathrm{R} \& \mathrm{D}$ expenditures in GDP in the world, with 4.2 percent, where the world av- 
erage is 1.2 percent. UAE and Qatar are leading countries in GCC, spending 0.49 percent and 0.47 percent of their GDP's on R \& D, respectively. Kuwait follows with 0.3 percent. Oman, Saudi Arabia and Bahrain are not visible in the picture with 0.17 percent, 0.07 percent and 0.04 percent $^{6}$. In the last decade, the GCC countries offer most generous funding for research projects on health and biotechnology sector as well as energy sector in an attempt to attract world-class researchers and to create several biomedical facilities throughout the region. The GCC countries have started to invest in biotechnology sector in mid-70 s. Julphar, which is the largest pharmaceutical manufacturer in MENA today, has founded in 1980 at UAE by the local government's attempts. The Dubai Healthcare Center in the UAE, the Harvard Medical School Dubai Center, and Education City in Qatar are other examples. Indeed, highly qualified infrastructure and funding potential for researchers exist in the region. However, only modest gains have been achieved. The GCC countries have had limited success in the global biotechnology environment.

The successful development process in biotechnology sectors of developing countries is related to many factors. Governments should manage the existing political will, which emerges from different reasons, through provision of physical and financial capital and supporting education system and educated individuals to cut the brain drain. Individual leadership is the engine of biotechnological products. The leaders in the sector are generally from universities and resilient against the difficulties in the innovation process. The innovation process requires the knowledge flow and close linkages among shareholders in the sector. Clusters of private enterprises increase the efficiency of the companies through building the required linkages. The technology transfer from universities to companies is also an important part of the knowledge network. The knowledge created by the individuals, universities or companies should be protected by the law so that the profit incentive for the innovator can be guaranteed. Relying on the reversed engineered biotechnological products can create a pervasive growth in the sector, which is not sustainable in the long-run. In general, the rule of law is a major determinant in the biotechnology market [32].

The GCC region has been fallen behind the developed countries in following the requirements of developing a successful biotechnology industry that are discussed above. As of 2011, none of the 26 pharmaceutical companies operating in the region is doing R \& D as a part of their operations in the GCC and the required technology is generally imported. The strong cooperation among the universities, private sector and government has never been developed. Although the education is the mostly financed and supported sector in the GCC region, the education quality and the skills mismatch are still problems. The efforts to appeal the interest of foreign human capital have been exerted within the last decades. However, high salaries have not been enough to make up for the limited collaborative opportunities, especially the difficulties that foreign re-

${ }^{6}$ UNESCO Institute for Statistics, Fact Sheet November 2015, No: 36. 
searchers have in finding the needed consultative and advisory services, in getting citizenship or in planning their retirements in the region. Moreover, R \& D is the first expense to cut when the economy stagnates, giving researchers little confidence in their ability to plan for long-term research projects [33].

In order to develop a solid research culture in biotechnology industry, supporting networks and communication infrastructures are necessary to encourage collaboration among different researchers and the sharing of ideas between academia and industry. In GCC countries, rather than an integrated R \& D culture, a fragmented research network has developed, which is unable to make efficient use of the substantial funding opportunities available. Due to the uncoordinated and diverse capital expenditures, the efforts in $\mathrm{R} \& \mathrm{D}$ activities have not accumulated consistently across the value chain.

In conclusion, the biotechnology sector is a well-suited industry to be stimulated as a chosen sector for the economic growth in the general policy framework of GCC governments. The policies that are supposed to be followed regarding the education, property rights, supporting the clusters are also compatible with the overall growth targets. The share of R \& D activities in GDP of GCC countries is increasing. The developing private sector and the improvements in the working environment are expected to solve the brain drain problem. However, the practice of policies is not significantly effective yet, and the legal environment related to the property rights and foreign researchers, the quality of institutions and supporting networks are still insufficient.

\section{Conclusions}

For decades, the governments of the GCC countries have been trying to improve their economies in a controlled way. Realizing that the insistence on strict policies of the oil revenue dependent and government led economy may have caused unexpected problems, GCC countries are likely to accept less control as time goes on. However, expecting GCC economies to be transformed into full market economies is not only an unrealistic but misguided expectation at the same time. Instead, GCC governments will continue to struggle to balance their need for economic development with their need for societal control. For entrepreneurs interested in doing business in the region, the region include challenges as well as opportunities raised by governmental control. Understanding the influences for GCC policy makers is important in order to understand the limits of their efforts to encourage entrepreneurs and the specific industries that they will be most capable of being successful with new policies.

This study is limited with the availability of the primary data that may reveal the conditions for the entrepreneurs in the region. A detailed international survey among nationals and foreign investors may enlighten many issues regarding the problems. Yet, the cases examined show that the large investments designed to develop technological industries will not be enough without serious efforts to address some of the fundamental issues. Some of the issues identified include 
apathetic workforce, lack of local skilled workers, lack of a native entrepreneurial culture, limited native participation in private sector, lack of effective R \& D networks, inability to attract and retain talented researchers, and policy-making constraints. Although large amounts of money are spent in GCC economies, only the entrepreneurial activities that challenge the limits of existing economic environment will probably be rewarding both the entrepreneurs and the economy as a whole in the future.

In the case of developing high-tech industries, such as biotechnology or clean energy, the problems of having a limited research culture, limited attractiveness for high-quality researchers, and limited collaboration among the community could be at least partially solved through private-sector activity. Although it is clearly very difficult to design a versatile and inclusive system, the GCC governments is sincere at least to subsidy institutions and companies that address these issues as a part of their operations. The challenges that rise from existing economic and political system are decelerating the transformation process, but at the same time, promising opportunities to entrepreneurs who are capable of using the governmental protections provided.

\section{References}

[1] Vorisek, D.L., Li, Q., Williams, P.D., Kose, A. and Ohnsorge, F.L. (2016) GCC Knowledge Note: Global Economic Trends. GCC Knowledge Series: Sharing Innovative Solutions in RAS Business, World Bank Group, Washington DC, 1-8.

[2] Schumpeter, J.A. (1934) The Theory of Economic Development: An Inquiry into Profits, Capital, Credit, Interest, and the Business Cycle. Vol. 55, Transaction Publishers, New Brunswick.

[3] Nelson, R.R. (2005) Technology, Institutions, and Economic Growth. Harvard University Press, Cambridge.

[4] Tyson, L.D.A. (1992) Who's Bashing Whom? Trade Conflict in High-Technology Industries. Vol. 7, Peterson Institute, Washington DC.

[5] North, D.C. (1990) Institutions, Institutional Change and Economic Performance. Cambridge University Press, Cambridge. https://doi.org/10.1017/CBO9780511808678

[6] Stiglitz, J.E., Lin, J.Y. and Monga, C. (2013) Introduction: The Rejuvenation of Industrial Policy. In: Stiglitz, J.E. and Lin, J.Y., Eds., The Industrial Policy Revolution I, Palgrave Macmillan, London, 1-15. https://doi.org/10.1057/9781137335173_1

[7] Hwang, H. and Powell, W.W. (2005) Institutions and Entrepreneurship. In: Alvarez, S.A., Agarwal, R. and Sorenson, O., Eds., Handbook of Entrepreneurship Research, Springer, US, 201-232. https://doi.org/10.1007/0-387-23622-8_10

[8] High, J. (2009) Entrepreneurship and Economic Growth: The Theory of Emergent Institutions. Quarterly Journal of Austrian Economics, 12, 3.

[9] El-Wassal, K.A. (2012) The Impact of Trade Liberalization on Trade Balance in Arab Countries. Journal of Economic and Social Research, 14, 1.

[10] Al-Iriani, M. (2007) Foreign Direct Investment and Economic Growth in the GCC Countries: A Causality Investigation Using Heterogeneous Panel Analysis. Topics in Middle Eastern and North African Economies, 9, 1-31.

[11] Isik, M. (2017) Making Innovation Development Policies Work for MENA: The 
Need for Entrepreneurship. In: Zgheib, P.W., Ed., Entrepreneurship and Business Innovation in the Middle East, IGI Global, Hershey, 74-104. https://doi.org/10.4018/978-1-5225-2066-5.ch005

[12] GCC: Economic Outlook-Spring 2016 World Bank (2017). http://www.worldbank.org/en/country/gcc/publication/economic-outlook-spring-2 $\underline{016}$

[13] Hertog, S. (2012) A Comparative Assessment of Labor Market Nationalization Policies in the GCC. In: Hertog, S., Ed., National Employment, Migration and Education in the GCC, Gerlach Press, Berlin, 100-102.

[14] Arab Knowledge Report: Youth and Localization of Knowledge, 2014. http://www.undp.org/content/dam/rbas/report/UNDP-GENERAL-REPORT-ENG. pdf

[15] Behar, A. and Mok, J. (2013) Does Public-Sector Employment Fully Crowd out Private-Sector Employment? IMF, Working Paper. http://www.imf.org/external/pubs/ft/wp/2013/wp13146.pdf

[16] Ahmed, M., Guillaume, D. and Furceri, D. (2012) Youth Unemployment in the MENA Region: Determinants and Challenges. Addressing the 100 Million Youth Challenge-Perspectives on Youth Employment in the Arab World in 2012, World Economic Forum, 5.

[17] (2017) Doing Business 2017: Equal Opportunity for All. World Bank, Washington DC. https://doi.org/10.1596/978-1-4648-0948-4

[18] Devarajan, S. and Mottaghi, L. (2014) Growth Slowdown Heightens the Need for Reforms. MENA Quarterly Economic Brief No. 2, World Bank, Washington DC, 112-118.

[19] Estache, A., Ianchovichina, E., Bacon, R. and Salamon, I. (2013) Infrastructure and Employment Creation in the Middle East and North Africa. World Bank Publications, Washington DC. https://doi.org/10.1596/978-0-8213-9665-0

[20] Samman, H. and Shahnawaz, S. (2014) Financial Services and the GATS in the GCC: Problems and Prospects. Review of Middle East Economics and Finance, 10, 293-316. https://doi.org/10.1515/rmeef-2013-0050

[21] Gackstatter, S., Kotzemir, M. and Meissner, D. (2014) Building an Innovation-Driven Economy-The Case of BRIC and GCC Countries. Foresight, 16, 293-308. https://doi.org/10.1108/FS-09-2012-0063

[22] Goddard, S., Delghandi, M., Dobretsov, M., Al-Oufi, H., Al-Habsi, S. and Burgess, J.G. (2015) The First GCC Marine Biotechnology Symposium: Emerging Opportunities and Future Perspectives. Marine Biotechnology, 17, 285-289. https://doi.org/10.1007/s10126-015-9617-0

[23] Reiche, D. (2010) Energy Policies of Gulf Cooperation Council (GCC) CountriesPossibilities and Limitations of Ecological Modernization in Rentier States. Energy Policy, 38, 2395-2403. https://doi.org/10.1016/j.enpol.2009.12.031

[24] Saadouli, N. (2010) Mechanisms for Seeking and Developing Young Entrepreneurs in Kuwait and the GCC Region. Journal of Asia Entrepreneurship and Sustainability, 6, 67 .

[25] http://gulfnews.com/news/gulf/kuwait/absent-public-sector-employee-gets-regularsalary-for-10-years-in-kuwait-1.1927309

[26] Wüstenhagen, R. and Menichetti, E. (2012) Strategic Choices for Renewable Energy Investment: Conceptual Framework and Opportunities for Further Research. Energy Policy, 40, 1-10. https://doi.org/10.1016/j.enpol.2011.06.050 
[27] Cato, M.S., Arthur, L., Keenoy, T. and Smith, R. (2008) Entrepreneurial Energy: Associative Entrepreneurship in the Renewable Energy Sector in Wales. International Journal of Entrepreneurial Behavior \& Research, 14, 313-329. https://doi.org/10.1108/13552550810897678

[28] Ferroukhi, R., Khalid, A., Hawila, D., Nagpal, D., El-Katiri, L., Fthenakis, V. and Al-Fara, A. (2016) Renewable Energy Market Analysis-The GCC Region. IRENA, Abu Dhabi.

http://www.irena.org/DocumentDownloads/Publications/IRENA_Market_GCC_20 16.pdf

[29] Tolba, M.K. and Saab, N.W. (2009) Arab Environment Climate Change. Arab Forum for Environment and Development (AFED) with Technical Publications and Environment and Development Magazine, Beirut, 7-8.

[30] Davis, J.M., Fedelino, A. and Ossowski, R. (2003) Fiscal Policy Formulation and Implementation in Oil-Producing Countries. International Monetary Fund, Washington DC.

[31] Losman, D.L. (2010) The Rentier State and National Oil Companies: An Economic and Political Perspective. The Middle East Journal, 64, 427-445. https://doi.org/10.3751/64.3.15

[32] Thorsteinsdóttir, H., Quach, U., Daar, A.S. and Singer, P.A. (2004) Conclusions: Promoting Biotechnology Innovation in Developing Countries. Nature Biotechnology, 22, DC48-DC52. https://doi.org/10.1038/nbt1204supp-DC48

[33] Lerer, L. and Bowman, B. (2011) Beyond Investment: Advancing the Biotechnology Sector in the Countries of the Gulf Cooperation Council (GCC). Journal of Com mercial Biotechnology, 17, 53-72. https://doi.org/10.1057/jcb.2010.25 